\title{
The form factor of alpha-naphthyl acetate esterase- positive cells in non-Hodgkin's lymphomas and reactive lymph nodes
}

\author{
J CROCKER, EL JONES, RC CURRAN
}

From the Department of Pathology, The Medical School, University of Birmingham, Edgbaston, Birmingham, B15 2TJ

SUMMARY The shape of alpha-naphthyl acetate esterase (ANAE)-positive cells (other than T lymphocytes) has been measured in 40 lymph nodes. The specimens comprised 15 high-grade lymphomas, 15 low-grade lymphomas and 10 reactive lymph nodes. The parameter used for the measurement of shape was form factor (FF), which is readily calculated by the Reichert-Jung (Kontron) MOP-AMO $\mathrm{Aser}_{3}$-controlled image analyzer. Perfectly round cells have an FF value of $1 \cdot 0$, whereas the FF of irregularly-shaped cells diverges from unity. It has been demonstrated that the ANAE-positive cells in high-grade lymphomas have mean values for FF of $0 \cdot 8-0 \cdot 9$, whereas in low-grade lymphomas and reactive nodes the mean value is $0 \cdot 4-0 \cdot 5$. Thus, high-grade lymphomas contain many more rounded ANAE-positive macrophage type cells than do low-grade lymphomas and reactive nodes. In the latter two types of specimen there is an excess of branching and spindle-shaped ANAE-positive cells.

During a study of the numbers of alpha-naphthyl acetate esterase (ANAE)-positive cells in nonHodgkin's lymphomas (NHL) ${ }^{1}$ it was subjectively noted, in passing, that these cells were, in high-grade NHL, more often of the rounded, tingible-body type. Conversely, the impression was gained that branching forms of ANAE-positive cells outnumbered the rounded forms in low-grade NHL and in reactive nodes. To test this impression objectively, 40 specimens were examined using the Reichert-Jung (Kontron) MOP- $\mathrm{AMO}_{3}$ usercontrolled ("interactive") image analyzer. One of the parameters measurable by means of the MOP-AMO is that of form factor (FF). ${ }^{2}$ The FF of a structure is a measurement whose value is given by the simple formula:

$$
F F=\frac{4 \pi A}{P^{2}}
$$

$\mathrm{A}=$ area of structure.

$\mathbf{P}=$ perimeter of structure.

For a perfect circle, FF $=1 \cdot 0$. Deviations from a circle, whether elliptical or, for example, dendritic or spindle-shaped, result in an FF value of less than 1.0.

Accepted for publication 26 October 1982
Highly complex dendritic structures have values approaching $0 \cdot 2$ or even $0 \cdot 1$. Therefore, FF appears to be a useful means of determining the degree of roundness of structures such as ANAE-positive cells.

\section{Material and methods}

\section{LYMPH NODES}

Forty lymph nodes were examined, from the same number of patients. These were histologically diagnosed and typed according to the Kiel classification $^{3}$ prior to measurement of the FF of ANAE-positive cells. All measurements were performed "blind," the specimens being coded by numbers. There were six centrocytic, nine centrocytic-centroblastic, two centroblastic, nine immunoblastic, two lymphoblastic and two unclassifiable high-grade malignancy lymphomas. Ten "reactive" lymph nodes were also examined, showing follicular hyperplasia with or without sinus histiocytosis (Table).

FIXATION AND STAINING

These were performed as described before ${ }^{14}$; lymph nodes were collected immediately after surgical removal, cut into $2 \mathrm{~mm}$ thick slices with a degreased 
Specimens examined

\begin{tabular}{ll}
\hline Diagnosis & Noofspecimens \\
\hline Reactive lymph nodes & 10 \\
Centrocytic lymphoma & 6 \\
Centrocytic-centroblastic lymphoma & 9 \\
Centroblastic lymphoma & 2 \\
Immunoblastic lymphoma & 9 \\
Lymphoblastic lymphoma & 2 \\
Unclassifiable high-grade lymphoma & 2 \\
\hline
\end{tabular}

razor blade and fixed in cold $\left(4^{\circ} \mathrm{C}\right)$ formol-calcium for $24 \mathrm{~h}$. The slices were then transferred to gum-sucrose solution for a further $24 \mathrm{~h}$, then sectioned in a cryostat at $6 \mu \mathrm{m}$ thickness and stained for ANAE by the simultaneous coupling azo-dye technique. ${ }^{4}$ Slices were also fixed in $10 \%$ formol saline at room temperature and dehydrated and embedded in paraffin wax. Sections were cut at $2-3 \mu \mathrm{m}$ and stained by Harris's haematoxylin and eosin for diagnostic histology.

\section{MEASUREMENT OF FORM FACTOR}

The use of the MOP-AMO ${ }_{3}$ has previously been described in detail by the authors. ${ }^{1567}$ The microprocessor was programmed to measure $\mathrm{FF}$ in steps of 0.05 units, from 0.05 to 1.0 and to give the data as a linear histogram, with their mean value. One hundred ANAE-positive cells' images were outlined (under a $\times 100$ oil immersion objective) using the graphic tablet and sensitive pen. Fields were selected randomly and all ANAE-positive cells in each field were outlined (excluding lymphocytes bearing punctate enzyme activity, which include some $\mathrm{T}$ lymphocytes ${ }^{49}$ ). In addition to linear histograms, the data for each specimen were plotted as cumulative percentages on logarithmic probability plot paper. The latter technique is useful as a means of demonstrating different populations of cells. ${ }^{610}$

\section{Results}

Cell outlines were clearly defined by the ANAE method and their images were easily and accurately outlined on the graphic tablet using the $\times 100$ oil immersion objective lens. Typical FF values for cells of differing shape are shown in Figs. 1 and 2; clearly these have values which correspond to their roundness or degree of dendritic shape.

Figure 3 shows the mean FF values for the 15 high-grade and 15 low-grade lymphomas; the 10 reactive lymph nodes' values are also shown. The mean values for $\mathrm{FF}$ in high-grade lesions tend to be in the range of $0 \cdot 8-0.9$; this is much greater than the values for low-grade lymphomas, whose $\mathrm{FF}$ values are usually 0.5 (one having a value of 0.4 ). The
Crocker, Jones Curran

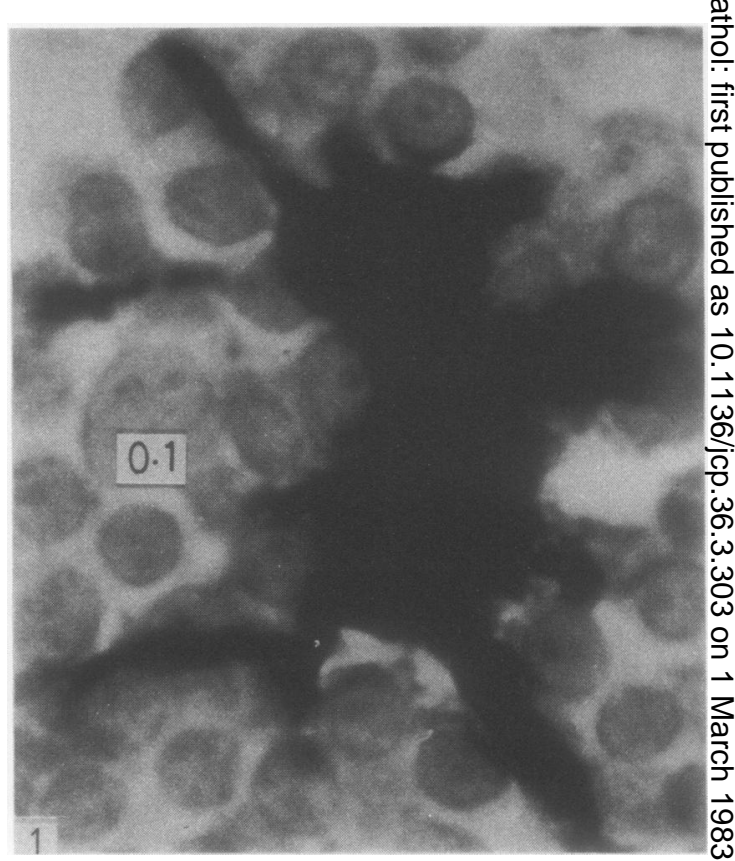

Fig. 1 An ANAE-positive branching cell with a very low value of $F F(0 \cdot 1)$.

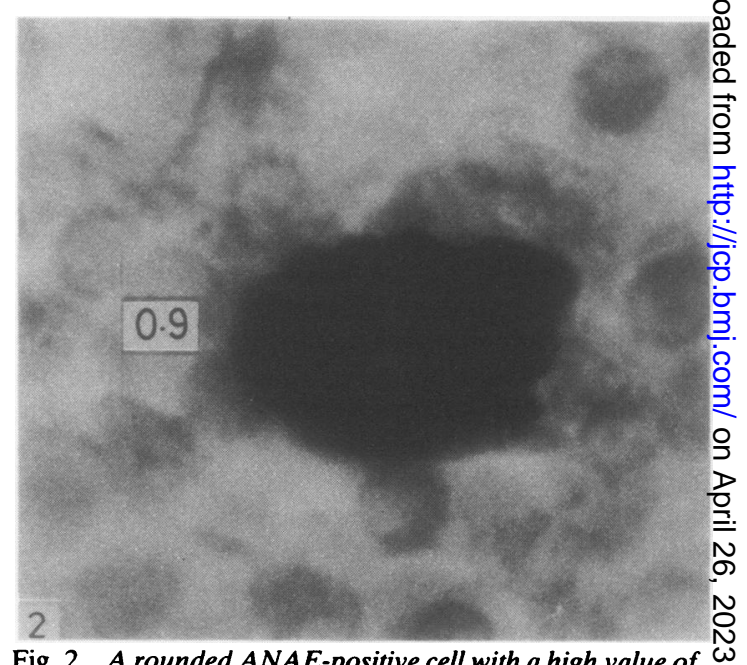

Fig. 2 A rounded ANAE-positive cell with a high value of $F F(0 \cdot 9)$.

ANAE-positive cells in reactive lymph nodes alsơ have an FF of 0.5 (one being 0.4 ). Thus the mean $\mathrm{FF}_{\mathrm{O}}$ for low-grade lymphomas is very similar to that of reactive nodes.

Figure 4 shows the data plotted on cumulative probability paper. All specimens have non-linea? plots and it is possible to project two lines through 


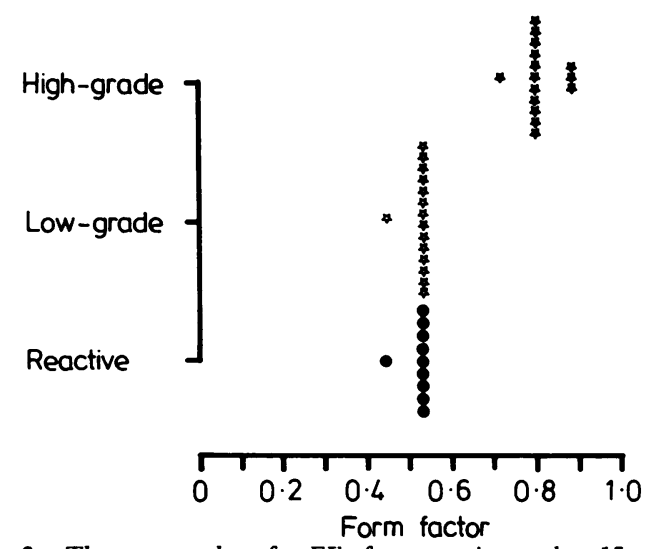

Fig. 3 The mean values for FF of ten reactive nodes, 15 specimens of low-grade and 15 specimens of high-grade lymphoma.

each series of data. This implies that, by virtue of their FF values, two populations of ANAE-positive cells exist in all of the specimens, some with more rounded and some with more branching (or, at least less rounded) shapes. The plots for high-grade lymphomas lie in a cluster on the far right of the $\mathrm{x}$-axis, towards a FF of unity. This contrasts with the plots for low-grade lymphomas and reactive nodes, whose plots lie in a large mixed cluster, nearer to the mid-range of FF.

\section{Discussion}

Form factor is readily and accurately measured by the MOP-AMO $\mathrm{Aut}_{3}$ is a parameter that has been used only rarely in past studies. However, there is a recent description of the usefulness of FF measurement (with the MOP-1 system) in a study of cellular size and shape in normal and diseased skeletal muscle. ${ }^{2}$

In the field of lymphoma research, another parameter of shape has been used to distinguish early lesions of mycosis fungoides from chronic benign skin lesions. This parameter is the nuclear contour index (NCI) which is given by the relation:

$$
\mathrm{NCI}=\frac{\text { perimeter }}{\sqrt{\text { area }}}
$$

The NCI gives values which reflect the degree of nuclear indentation (a feature of, for example, Sézary cells). The NCI of isolated lymph node cells has also been measured in specimens of mycosis fungoides and Sézary's syndrome. ${ }^{112}$ In a subsequent study, ${ }^{13}$ quantitative electron microscopy was used to measure $\mathrm{NCI}$ in skin biopsies from 109 patients, 77 of whom had chronic benign inflammatory disease and 16 had mycosis fungoides. A further 16 patients had

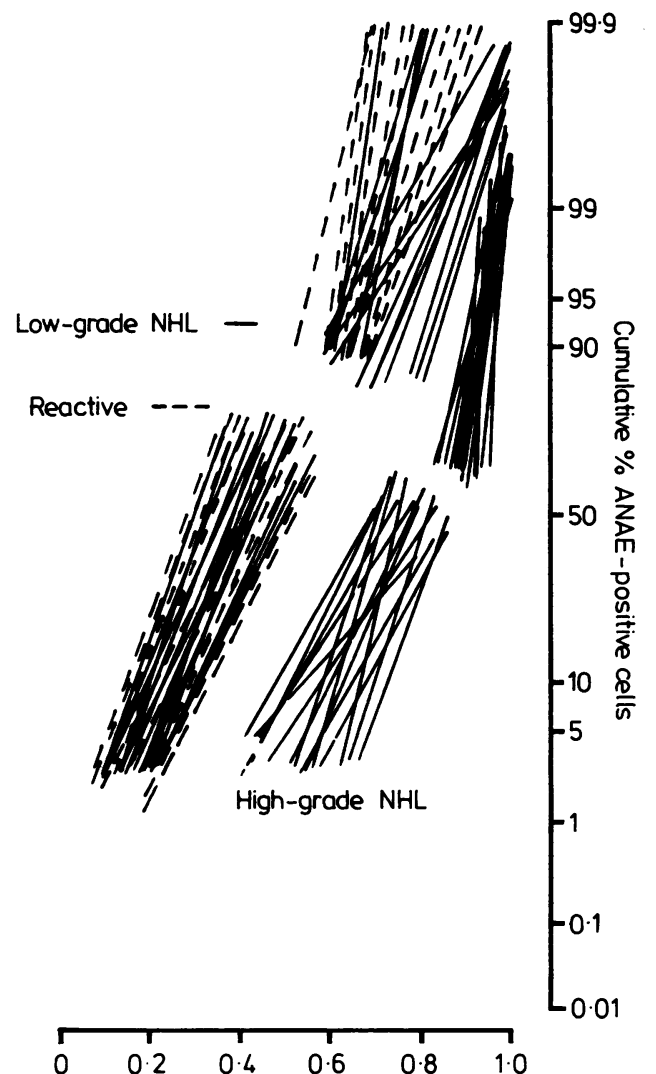

Fig. 4 Cumulative probability plots for the 40 specimens measured. The FF values lie along the $x$-axis. Plots for highgrade lymphomas lie more to the right of the $x$-axis, in a cluster, separate from the large mixed cluster of values for low-grade lymphomas and reactive nodes, whose values for FF lie nearer to the mid-range.

infiltrates, the nature of which was uncertain. A "false-negative" rate of $50 \%$ was found for early mycosis fungoides lesions.

It appears, therefore, that measurements of shape as well as size are potentially useful in histopathology. FF is readily measurable by the MOP- $\mathrm{AMO}_{3}$ and is well suited to measurements of shape of structures such as ANAE-positive cells in lymphoid tissue. On subjective grounds the shape of these cells varies, although cells (such as tingible-body macrophages) which appear rounded in haematoxylin and eosinstained sections often have small cytoplasmic processes when stained for ANAE. Nonetheless, this sort of cell is morphologically quite different from the highly branching ANAE-positive macrophage (or, of course, the very weakly ANAE-positive dendritic reticulum cell). A striking "starry-sky" appearance with mainly round macrophages is seen, for example, 
in Burkitt-type lymphoblastic lymphoma which is a high-grade variety of NHL. Such rounded macrophages have a value of FF approaching unity.

The results of this study show that, on the basis of FF, the ANAE-positive macrophage-type cells in reactive nodes and low-grade NHL tend to be more often of the branching type than in high-grade lymphomas, where more rounded esterase-positive cells predominate. The probability plots show that, as might be expected, all specimens possess two populations of such cells, of both branching and rounded type. The plots for high-grade lymphomas are shifted towards a FF of 1.0 to a greater extent than those for reactive specimens and low-grade lymphomas, with many more cells in the range of 0.8 to $1 \cdot 0$.

The significance of these findings is uncertain, but it is clear that FF values of ANAE-positive cells can usefully discriminate between high- and low-grade lymphomas, when correlated with morphological diagnosis using the Kiel classification. However, there is no discrimination between low-grade lymphomas and reactive nodes. It may be, in some instances, that rounded macrophages are in a highly "activated" state and are mounting an attack on highgrade lymphoma cells, where there is cell death and necrosis. In low-grade lymphomas, where growth is less rapid, the branching forms seen in normal and reactive nodes are predominant. It is possible that in the high-grade lymphomas there is an in-pouring of rounded, "reactive" macrophages, their numbers being greatly in excess of those present in normal or reactive lymphoid tissue. These rounded macrophages may be much less "specialised" or"differentiated" than their branching counterparts.

The ANAE technique offers a major advantage over the use of immunohistochemical methods (such as staining for muramidase or alpha-1-antitrypsin) for the study of size or shape of macrophages. This is because the frozen sections used for ANAE-staining are thicker than those utilised in immunohistochemistry; thus the extent of branching processes is more often evident with the former than the latter method.

It is possible that factors such as mitotic activity of lymphoid cells adjacent to the ANAE-positive cells may affect the shape of the latter. Certainly, in two studies of reactive lymphoid follicles ${ }^{1415}$ using metalophil staining methods, it was noticed that rounded macrophage-type cells were predominant in the lower centroblast rich part of the follicle, where mitoses are frequent. Conversely, in the upper parts of the reactive follicle, where fewer mitoses are seen and centrocytes predominate, metalophil branching macrophages and dendritic reticulum cells were observed. Thus, local microenvironmental factors may, in some unknown fashion, influence macro phage shape in lymphoid follicles.

We wish to thank Mrs Mary Williams for her excellento technical assistance and Miss Angela Wright fo: typing the manuscript. This study was supported by grants from the Endowment Fund Medical Research Committee of the Central Birmingham Health District and The Royal Society.

\section{References}

Crocker J, Jones EL, Curran RC. $\alpha$-naphthyl acetate esterase-positive cells in non-Hodgkin' lymphomas and reactive lymph nodes. J Clin Pathof 1982;35: $1066-8$.

${ }^{2}$ Round JM, Jones DA, Edwards RHT. A flexible microprocessof system for the measurement of cell size. J Clin PathoD 1982;35:620-4.

${ }^{3}$ Lennert K. Malignant lymphomas other than Hodgkin's disease New York: Springer-Verlag, 1978.

+ Crocker J. The enzyme histochemistry of lymphoid and non lymphoid cells in the human palatine tonsil: a basis for the study of lymphomas. J Pathol 1981;134:81-95.

${ }^{5}$ Crocker J, Curran RC. A quantitative study of the immunoglobulino containing cells in trephine samples of bone marrow. J Clin w Pathol 1981;34: 1080-2.

${ }^{6}$ Crocker J, Jones EL, Curran RC. Study of nuclear diameters in non-Hodgkin's lymphomas. J Clin Pathol 1982;35:954-8.

' Crocker J, Jones EL, Curran RC. A quantitative study ō̆ $\alpha$-naphthyl acetate esterase-positive cells in Hodgkin's disease J Clin Pathol 1982;35:1301-6.

${ }^{*}$ Mueller J, Brun del Re G, Buerki H, Keller H-U, Hess MW Cottier H. Non-specific acid esterase activity: a criterion foo differentiation of $\mathrm{T}$ and $\mathrm{B}$ lymphocytes in mouse lymph nodes 3 Eur J Immunol 1975;5:270-4.

${ }^{9}$ Zicca A, Leprini A, Cadoni A, Franzi AT, Ferrarini M, Gross CE. Ultrastructural localisation of alpha-naphthyl acid esterase in human $\mathrm{T}_{\mathrm{M}}$ lymphocytes. Am J Pathol 1981;105:40-6.

${ }^{10}$ Berry RE. Normal values in pathology. In: Sommers SC, ed? Pathology annual London: Butterworths, 1969:71-88.

" Meijer CJLM, Van der Loo EM, Van Vloten WA, Scheffer E? Corneliss CJ. Early diagnosis of mycosis fungoides and Sézary syndrome by morphometric analysis of lymphoid cells in the skin. Cancer 1980;46:150-65.

12 Van der Loo EM, Cornelisse CJ, Van Vloten WA, Van der Velde EA, Scheffer E, Meijer CJLM. Diagnostic morphometry of isolated lymph node cells from patients with mycosis fungoide? and Sézary's syndrome. Virchows Archiv B 1980;33:107-16.

${ }^{13}$ McNutt NS, Crain WR. Quantitative electron microscopi comparison of lymphocytic nuclear contours in mycosis fungoides and in benign infiltrates in the skin. Cancet 1981;47:698-709.

${ }^{14}$ Curran RC, Jones EL. Immunogloblin-containing cells in human tonsils as demonstrated by immunohistochemistry. Clin Exp Immunol 1977;28:103-15.

is Curran RC, Gregory J, Jones EL. The distribution of immunoglobulin and other plasma proteins in human reactives lymph nodes. J Pathol 1982;136:307-32.

Requests for reprints to: Dr J Crocker, Department ofึ Pathology, The Medical School, Birmingham B15 2TJ 2 England. 